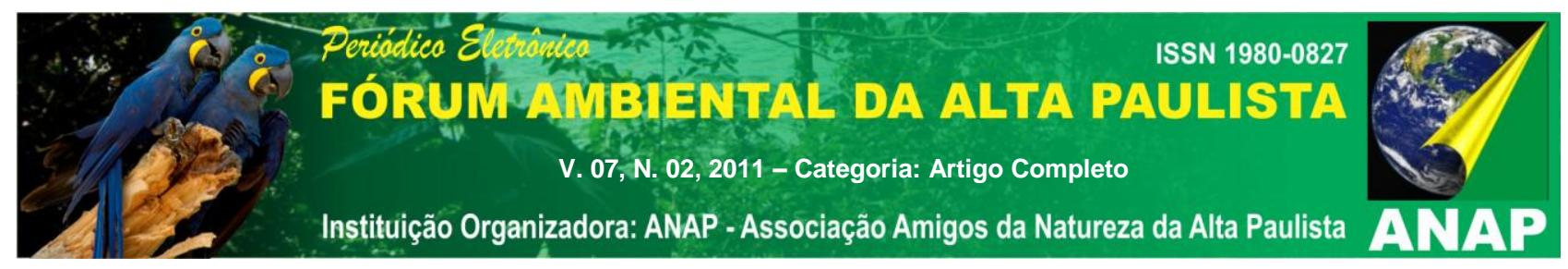

\title{
OS PEQUENOS POTENCIAS HIDRELÉTRICOS COMO VETOR DE DESENVOLVIMENTO SUSTENTÁVEL
}

\author{
Mariana Wagner de Toledo Piza ${ }^{1}$
}

Osmar de Carvalho Bueno ${ }^{2}$

RESUMO: Os países e regiões precisam de energia elétrica para se desenvolver. Por isso é necessário buscar fontes limpas de energia que não causem grande impacto ao meio ambiente, principalmente à água que é fundamental a vida na terra. O presente trabalho tem como objetivo expor a possibilidade de aumentar a diversificação da geração de energia hidrelétrica e foi realizado por meio de levantamentos bibliográficos e acesso de agências ligadas ao governo. Assim demonstrou as vantagens que as Pequenas Centrais Hidrelétricas trazem para a composição da matriz energética.

Palavras-chave: Energias Renováveis. PCHs. Sustentabilidade.

\section{INTRODUÇÃO}

\footnotetext{
${ }_{1}^{1}$ Administradora, Aluna especial de Mestrado em Energia na Agricultura pelo Programa de PósGraduação Energia na Agricultura - Faculdade de Ciências Agronômicas - UNESP. E-mail: marywagner.adm@gmail.com

${ }^{2}$ Engenheiro Agrônomo, Faculdade de Ciências Agronômicas - UNESP. Professor Adjunto. Email: osmar@fca.unesp.br
} 


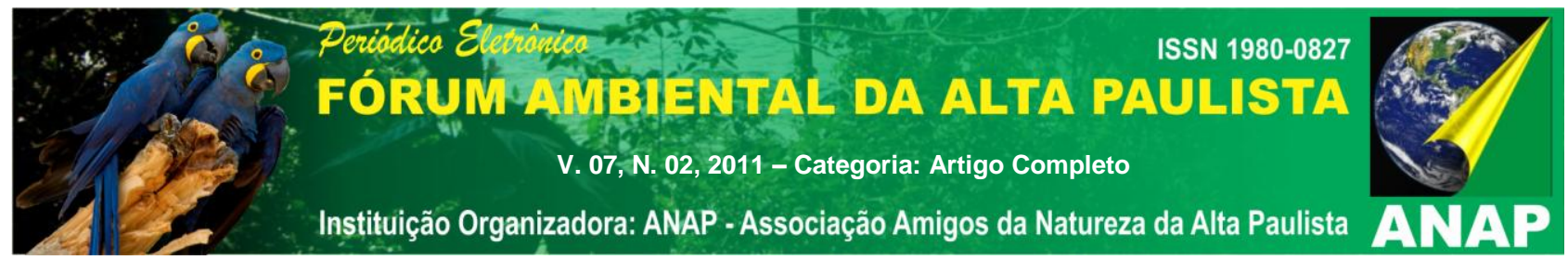

A água é fundamental à vida e mantém o equilíbrio do meio ambiente, porém era visto por todos como um recurso infinito.

O Brasil possui situação privilegiada em relação à sua disponibilidade hídrica, porém, aproximadamente $70 \%$ da água doce do país encontram-se na região amazônica, que é habitada por menos de $5 \%$ da população. A idéia de abundância serviu durante muito tempo como suporte a "cultura do desperdício" da água disponível, à sua pouca valorização como recurso e ao adiamento de investimentos necessários à otimização de seu uso (SETTI, 2001).

Devido ao crescente perigo de escassez vem-se observando uma maior preocupação com seu manejo e utilização por parte do Brasil e dos demais países, e vem sendo realizados investimentos para a manutenção da qualidade e quantidade deste recurso no planeta.

É necessário que haja um planejamento para o uso da água levando em consideração os usos que ainda não foram feitos no curso do rio, mas que poderão ser realizados sem que o uso atual cause impedimento. Assim, é preciso por em prática a Lei no 9.433/97, parágrafo IV que diz: "a gestão dos recursos hídricos deve sempre proporcionar o uso múltiplo das águas entre suas demandas em igualdade de condições" (BRASIL, 1997).

A energia gerada através de hidrelétricas propicia esse uso, pois a água é devolvida ao rio na mesma quantidade e qualidade que foi retirada. Porém os empreendimentos hídricos causam impactos proporcionais a seu tamanho.

Atualmente vemos a importância do Brasil explorar seu potencial hídrico por meio de pequenos aproveitamentos como as $\mathrm{PCHs}$ (Pequenas Centrais Hidrelétricas) a fio d'água levando em conta a mitigação dos impactos ambientais e as demais vantagens que ela traz.

\section{RECURSOS HÍDRICOS}

A água está presente não só na constituição dos animais como também em todas suas atividades inclusive e principalmente sua sobrevivência. Para o homem, ela propicia bem estar e desenvolvimento socioeconômico. 


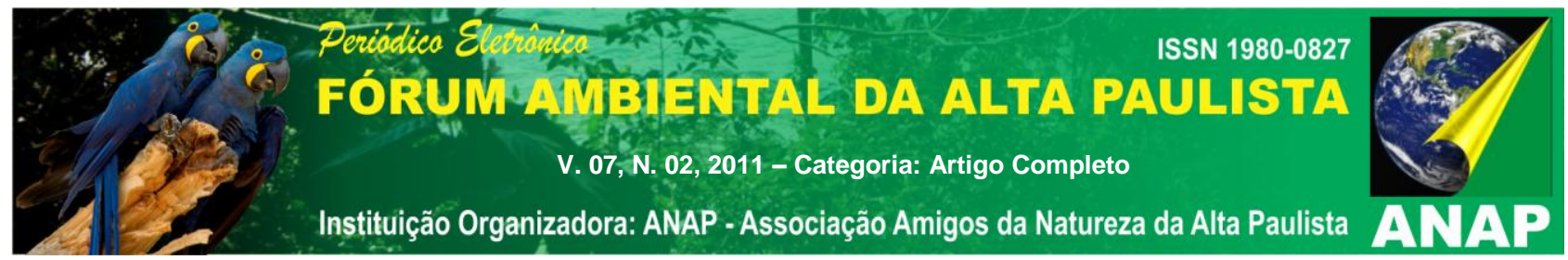

Este recurso era utilizado sem tanta preocupação, como se fosse um recurso ilimitado. Porém, com o passar do tempo a preocupação com o modo de utilização da água vem sendo um assunto de estudo e debate.

No Brasil a questão de uso sustentável da água vem sendo trabalhada em todos os níveis da esfera pública, no setor privado e no terceiro setor na perspectiva de haver ações integradas para a manutenção da quantidade e qualidade da água.

O Brasil detém cerca de $12 \%$ das reservas de água doce do mundo e visando a manutenção de sua qualidade e quantidade, lançou em 1934 o "Código de Águas", sendo o primeiro dispositivo legal voltado especificamente para a água. Porém, conforme as necessidades da época privilegiaram-se o setor energético e a navegação (CEDRAZ, 2000).

Em 1997, foi sancionada a Lei no 9.433 em 8 de Janeiro, que institui a Política Nacional de Recursos Hídricos (PNRH), conhecida por "Lei das Águas", criando o Sistema Nacional de Gerenciamento de Recursos Hídricos (SNGRH), trazendo como principal fundamento o conceito que a água é um bem de domínio público, recurso natural limitado, dotado de valor econômico, que em situações de escassez, o uso prioritário dos recursos hídricos deve ser o consumo humano e animal (BRASIL, 1997).

Em 17 de Julho de 2000 foi sancionada a Lei nº 9.984, criando a ANA (Agência Nacional da Água) que tem como objetivos implementar, em sua esfera de atribuições, a $\mathrm{PNRH}$, promover a gestão descentralizada e participativa, em sintonia com os órgãos e entidades que integram o Sistema Nacional de Gerenciamento de Recursos Hídricos, implantar os instrumentos de gestão previstos na Lei 9.433/97, dentre eles, a outorga preventiva e de direito de uso de recursos hídricos, a cobrança pelo uso da água e a fiscalização desses usos, e ainda, buscar soluções adequadas para os mais graves problemas do país: as secas prolongadas (especialmente no Nordeste) e a poluição dos rios (MMA, 2011).

A forma da utilização dos recursos hídricos pode ser classificada como consultivo e não consultivo. Segundo SETTI (2001) a utilização é consultiva quando a água é captada em seu curso natural e apenas parte dela retorna. Já a forma não consultiva é quando a água retirada de seu curso retorna integralmente (GAVIÃO et al, 2003). 


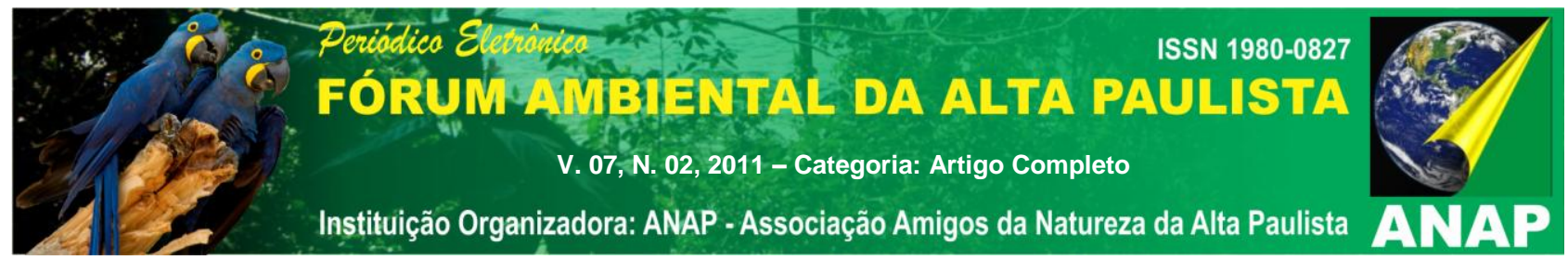

Para assegurar o controle quantitativo e qualitativo dos usos da água e o efetivo exercício dos direitos de acesso à água é utilizada a outorga. Esta trata-se de um dos seis instrumentos da Política Nacional de Recursos Hídricos, estabelecidos no inciso III, do art. 5ำ da Lei Federal ํo 9.433/97.

Cabe à ANA outorgar, através de autorização, o direito de uso de recursos hídricos em corpos d'água de domínio da União, bem como emitir outorga preventiva. Também é competência da ANA a emissão da reserva de disponibilidade hídrica para fins de aproveitamentos hidrelétricos e sua conseqüente conversão em outorga de direito de uso de recursos hídricos.

\section{ENERGIA ELÉTRICA}

Segundo a ANEEL (2008) uma das variáveis para que um país seja considerado desenvolvido é a facilidade de acesso da população a serviços de infra estrutura, como saneamento básico, transportes, portos, aeroportos, geração de energia elétrica, etc.

A energia é fator determinante para o desenvolvimento social e econômico ao fornecer melhores condições de vida e de produção, facilitando as ações que as pessoas desenvolvem (ANEEL, 2008).

Assim, todos os países buscam fontes para gerar energia elétrica e se desenvolverem. Cada um tem uma vocação dependendo de sua geografia, seu clima e seu desenvolvimento tecnológico.

Segundo Filho (2004) o Brasil ocupa hoje uma posição privilegiada em matéria de matriz energética, com $82 \%$ de sua energia obtida de fontes renováveis, a maior parte de centrais hidrelétricas.

O país, em razão da localização geográfica privilegiada e da grande extensão territorial, possui a maior reserva de recursos hídricos do planeta e o maior potencial hidrelétrico. Mesmo ainda com este potencial subutilizado, o Brasil possui uma das matrizes energéticas consideradas mais "limpas" do mundo, isso por que, segundo EPE (2010), contou em 2009 com a participação de 76,9\% de fonte hidráulica.

No Gráfico 1 observa-se a oferta das fontes na matriz de energética elétrica brasileira. 

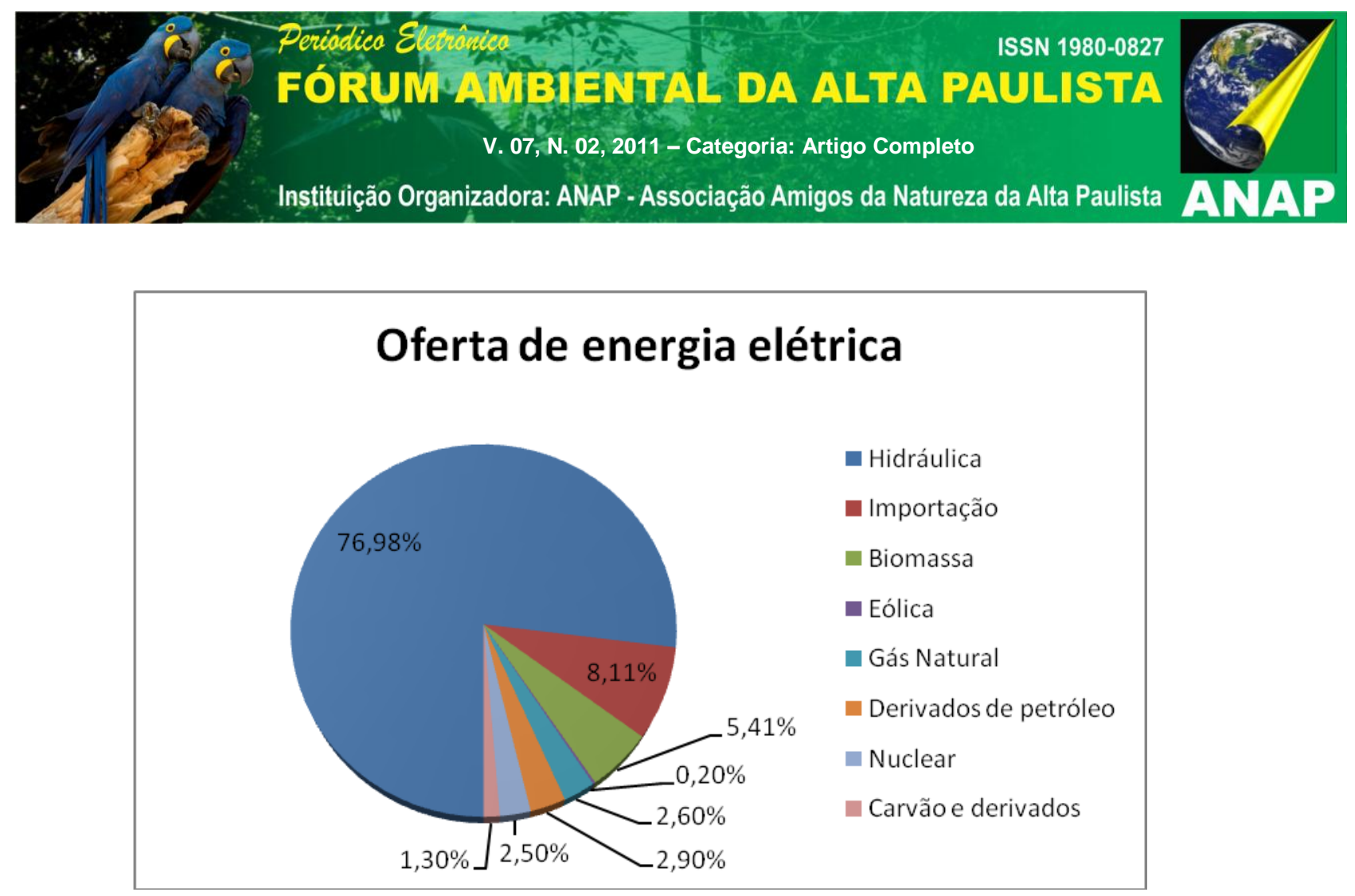

Gráfico 1

Fonte: EPE (2010)

A hidroenergia possui vários atrativos, destacando-se entre eles o alto rendimento de conversão. Segundo Palz (1981) o rendimento na conversão de água represada em eletricidade pode chegar a valores próximos de $90 \%$.

Segundo ANEEL (2011) a potência fiscalizada advinda da hidreletricidade no Brasil foi de $80.981 \mathrm{MW}$, sendo 0,2\% provenientes das CGHs (Centrais Geradoras Hidrelétricas, menores que $1 \mathrm{MW}$ de potência), 4,4\% provenientes das PCHs (Pequenas Centrais Hidrelétricas, de 1 a $30 \mathrm{MW}$ de potência) e 95,4\% gerados através das Usinas Hidrelétricas de Energia (acima de 30MW de potência). Esta composição da hidreletricidade é demonstrada no gráfico 2. 

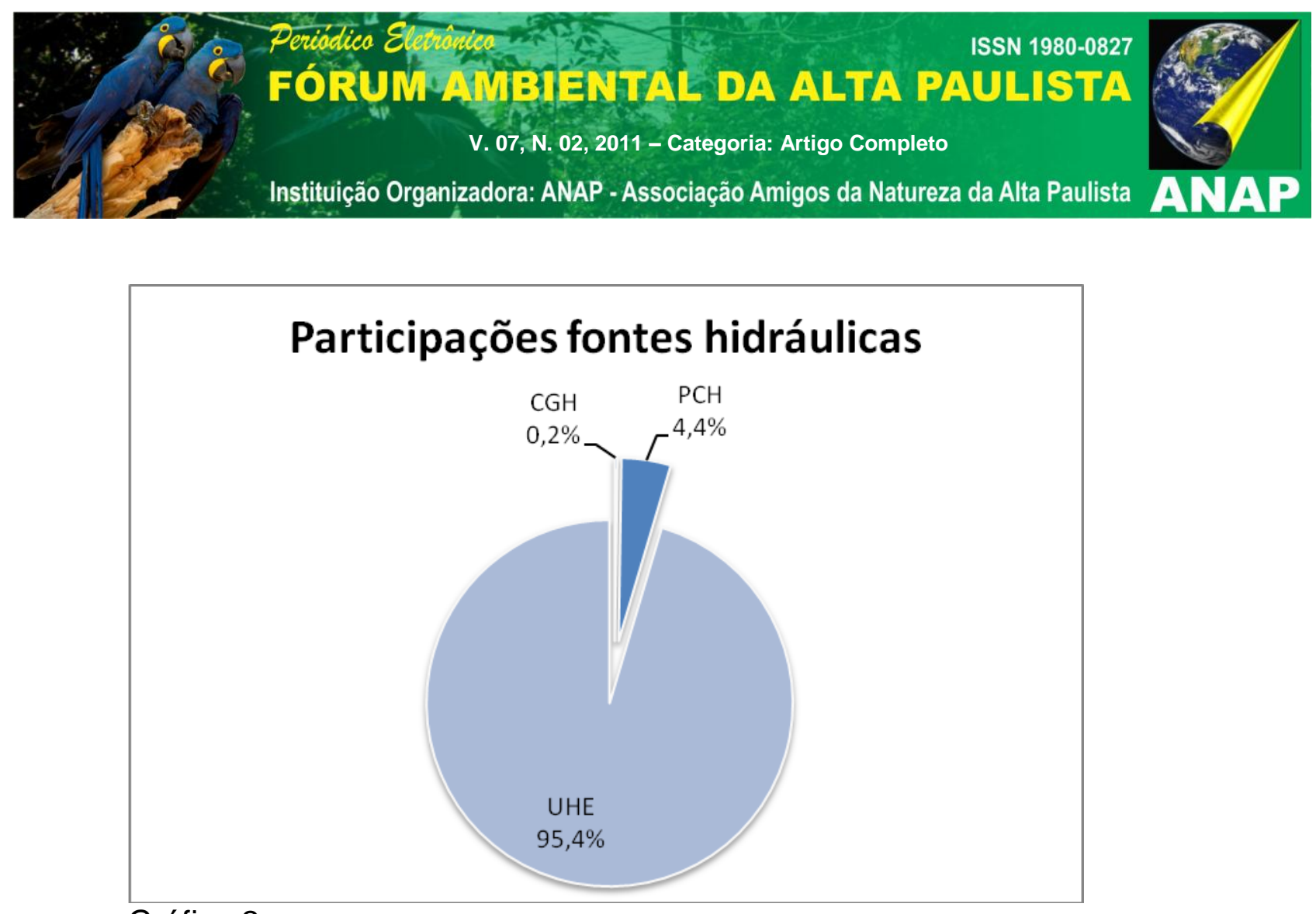

Gráfico 2

Fonte: ANEEL(2011)

Segundo Piza (2011), qualquer ação antrópica causa impactos no ambiente onde ela acontece, no caso das hidrelétricas não seria diferente.

A construção de barragens e formação dos reservatórios possui como conseqüências a perda de recursos florestais e da fauna terrestre e aquática, além da remoção da população e emissões de gases efeito estufa devido à emissão do metano pelas florestas inundadas (FREITAS et al., 2007).

Bermann (2007) destaca alguns problemas gerados pela implantação de usinas Hidrelétricas:

- alteração do regime hidrológico, comprometendo as atividades à jusante do reservatório;

- comprometimento da qualidade das águas devido ao caráter lêntico do reservatório, dificultando a decomposição dos rejeitos e efluentes;

- $\quad$ assoreamento dos reservatórios, em razão do descontrole no padrão de ocupação territorial nas cabeceiras dos reservatórios, submetidos a processos de desmatamento e retirada da mata ciliar;

- emissão de gases de efeito estufa, especialmente o metano, em virtude da decomposição da cobertura vegetal submersa definitivamente nos reservatórios; 
- aumento do volume de água no reservatório formado, decorrente da pressão sobre o solo e subsolo pelo peso da massa de água represada, em áreas com condições geológicas desfavoráveis provocando sismos induzidos;

- problemas de saúde pública, pela formação dos remansos nos reservatórios e devido à proliferação de vetores transmissores de doenças endêmicas.

Sendo assim é possível viabilizar os aproveitamentos menores que geram menor quantidade de energia, porém, tem sua concepção a fio d'água, geralmente com uma pequena barragem que desvia o curso do rio para o canal de adução. Assim, com reservatório pequeno pouca água é armazenada (UNIFEI, 2009), diminuindo os impactos negativos da hidroenergia como problema gerado pelo pela implantação dos médios e grandes reservatórios.

Parte do potencial hidrelétrico brasileiro pode ser explorada por meio de Pequenas Centrais Hidrelétricas (PCHs), usinas de menor porte, mas suficientes para abastecer pequenas e médias cidades ou indústrias, mediante o cumprimento de uma série de exigências socioambientais. Mais de $360 \mathrm{PCHs}$ somando capacidade energética superior a 3 mil MW operam no país. De acordo com a EPE e o Ministério de Minas e Energia, o potencial teórico de PCHs é de 25 mil MW (GREENPEACE, 2010).

HÍDRICA

\section{IMPORTÂNCIA DAS PCHS NA COMPLEMENTAÇÃO DA MATRIZ}

A resolução no 652, de 9 de Dezembro de 2003 estabelece os critérios para o enquadramento de aproveitamento hidrelétrico na condição de Pequena Central Hidrelétrica $(\mathrm{PCH})$. Será considerado com características de $\mathrm{PCH} \circ$ aproveitamento hidrelétrico com potência superior a $1 \mathrm{MW}$ e igual ou inferior a $30 \mathrm{MW}$, destinado a produção independente, autoprodução ou produção independente autônoma, com área do reservatório inferior a $3,0 \mathrm{~km}^{2}$.

O artigo $4^{\circ}$ complementa que o aproveitamento hidrelétrico que não atender a condição para a área do reservatório de que trata o artigo anterior, respeitados os limites de potência e modalidade de exploração, será considerado com características de $\mathrm{PCH}$, caso se verifique pelo menos uma das seguintes condições: 


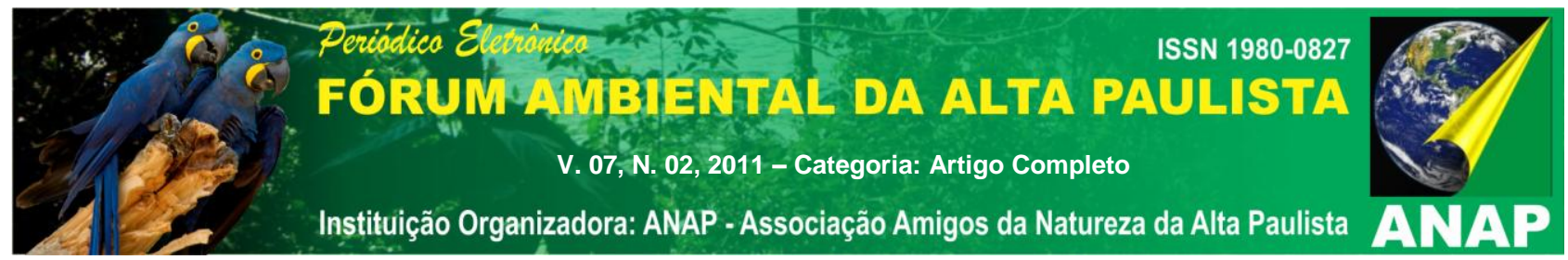

I - atendimento à inequação:

$A \leq 14,3 \times P / H b$

Sendo:

$\mathrm{P}=$ potência elétrica instalada em $(\mathrm{MW})$;

$A$ = área do reservatório em $(\mathrm{km} 2)$;

$\mathrm{Hb}=$ queda bruta em $(\mathrm{m})$, definida pela diferença entre os níveis d'água máximo normal de montante e normal de jusante;

II - reservatório cujo dimensionamento, comprovadamente, foi baseado em outros objetivos que não o de geração de energia elétrica.

O parágrafo primeiro adiciona que para o atendimento à ineqüação a que alude o inciso I, fica estabelecido que a área do reservatório não poderá ser superior a 13,0 $\mathrm{km}^{2}$ (ANEEL, 2011).

A importância das $\mathrm{PCHs}$ está no modo rápido e eficiente de promover a expansão da oferta de energia elétrica, objetivando suprir a crescente demanda verificada no mercado nacional. Esse tipo de empreendimento possibilita um melhor atendimento às necessidades de carga de pequenos centros urbanos e regiões rurais, sendo que pode também complementar o fornecimento realizado pelo sistema interligado. Por isso, além de simplificar o processo de outorga, o Governo concedeu uma série de benefícios ao empreendedor, para estimular os investimentos. (ANEEL, 2003).

Como a redução de $50 \%$ (cinqüenta por cento) nas tarifas de uso dos sistemas elétricos de transmissão e distribuição, para fins de comercialização da energia gerada pelos referidos empreendimentos, conforme os $\S \S 1^{\circ}$ e $5^{\circ}$ do art. 26 da Lei ํㅜ 9.427, de 1996, alterado pelo art. 8ํㅡㄹ da Lei oㅜ 10.762, de 2003, citado na resolução № 77 de 2004 (ANEEL, 2010).

Levando em consideração as PCHs no Brasil, segundo Prado (2010) o potencial hidráulico possível de exploração no país associado a este tipo de empreendimento é relativamente elevado (4\% da potência instalável total). Segundo o Plano 2015 da Eletrobrás, centrais de até $30 \mathrm{MW}$ de potência instalada representam um potencial de 9.456 MW. Hoje existem no Brasil 253 Pequenas Centrais Hidrelétricas em operação, somando 1.277 MW ao sistema interligado nacional, ou 1,35\%. O estado com maior concentração de PCH é Minas Gerais, com 77 usinas em operação somando 397,7MW. 


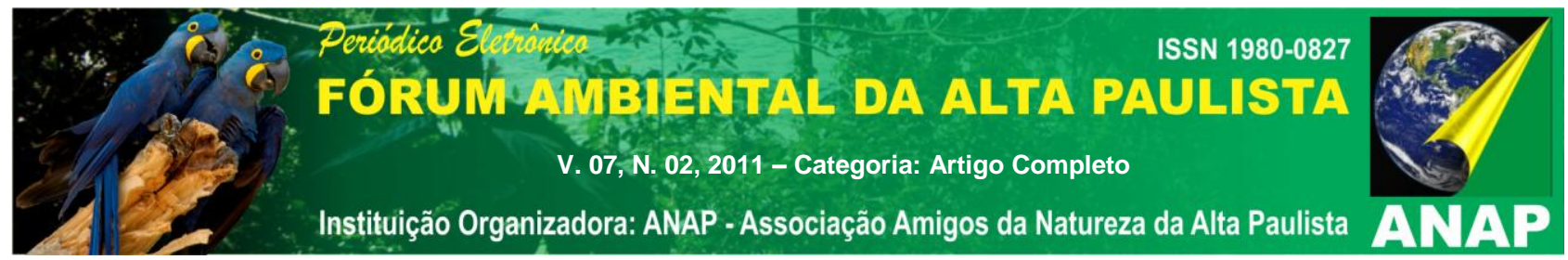

Segundo Muller (1995) especialmente em regiões rurais, as PCHs podem melhorar a qualidade de vida dos moradores, permitirem a instalação de pequenas indústrias e agregar elementos positivos para o funcionamento de escolas, centros de saúde, comunicações, comércio, etc. O próprio desenvolvimento seria incentivado por usos agregados dos reservatórios, por exemplo, o bombeamento elétrico d'água, também usado para aqüicultura e para a irrigação.

Embora as PCHs não sejam capazes de sozinhas, resolverem o problema energético do país, se destaca como alternativa limpa. A implantação é rápida se comparada aos grandes empreendimentos que levam de quatro a seis anos para ficarem prontas (Andrade, 2010).

\section{CONCLUSÃO}

É evidente que os países e regiões para se desenvolverem necessitam de energia elétrica, por isso é fundamental que busquem por fontes renováveis de energia de acordo com sua vocação.

O Brasil tem uma posição privilegiada se comparado a outros países, pois sua matriz energética é denominada renovável por ser baseada em fonte hidráulica.

É necessário lançar mão desta vocação levando em conta a manutenção dos recursos hídricos, o cuidado com o ambiente e o desenvolvimento regional. Para isso é necessário diversificar as fontes de energia hidráulica aumentando a geração por meio de pequenos potenciais, aproveitando as vantagens que esses trazem.

\section{REFERENCIAS}

ANDRADE, A. O papel das PCHs na economia catarinense. Florianópolis: Monografia de graduação, 2010. 71p.

ANEEL, Agência Nacional de Energia Elétrica - Atlas de Energia Elétrica - 3ª̣ed. Brasília: Cedoc, 2008. 233p.

ANEEL. Centro de documentação. Disponível em <http://www.aneel.gov.br/cedoc/res2003652.pdf>. Acesso em 18 jul. 2011. 


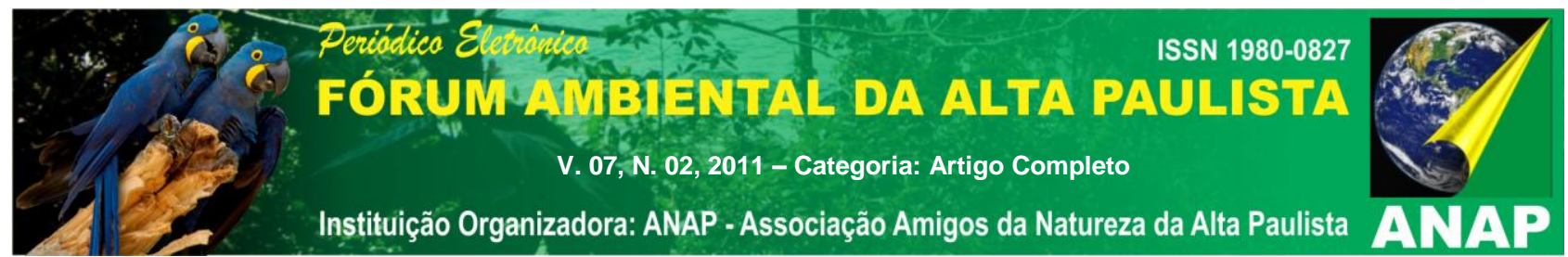

ANEEL. Guia do empreendedor de Pequenas Centrais Hidrelétricas. 1.ed. Brasília: Agência Nacional de Energia Elétrica, 2003. 704p.

ANEEL. Resolução ANEEL no 77, DE 18 DE AGOSTO DE 2004. Centro de Documentação, 2010. Disponível em: <http://www.aneel.gov.br/cedoc/bren2004077.pdf>. Acesso em 30 out.2010

BERMANN, C. Impasses e controvérsias da hidreletricidade. Estudos avançados. Vol.21, no.59, p.139-153. jan./abr. 2007.

BRASIL, Lei número 9.433 de 8 de JANEIRO DE 1997. Senado Federal, 2011. Disponível em

http://www6.senado.gov.br/legislacao/ListaPublicacoes.action?id=145411>. Acesso em 01 ago. 2011.

CEDRAZ,M. Gerenciamento dos recursos hídricos: um tema em discussão. In MUÑOS, H.R. (Ed.). Interfaces da Gestão de Recursos Hídricos: Desafios da Lei de Águas de 1997. Brasília, DF: SRH/ MMA, 2000. p. 110-126.

Empresa de Pesquisa Energética (EPE); Balanço Energético Nacional 2010 (BEN2010), Ministério de Minas e Energia; disponível em <www.mme.gov.br>. Acesso em 09 jun. 2011

ANEEL. Banco de Informações de Geração. 2011, disponível em <http://www.aneel.gov.br/aplicacoes/capacidadebrasil/capacidadebrasil.asp>. Acesso em 08 abr.2011.

FILHO, G.L.T. Dossiê Energia Positiva para o Brasil. 1.ed. Brasília: Greenpeace, 2004.76p.

FREITAS, M. A. V. et. al. Gestão da energia e dos recursos hídricos: uma visão socioambiental e interdisciplinar. In: RODRIGUES, S. C. C.; SANTANA, V. N.; BERNABÉ, V. L. (Org.) Educação, ambiente e sociedade: novas idéias e práticas em debate. Vitória: Companhia Siderúrgica de Tubarão - CST, 2007. 368 p.

Gavião, A. B. et al.O uso compartilhado da água - A necessidade de integração operacional. Bahia análise \& dados. Salvador, v. 13, n. ESPECIAL, p. 403-409, 2003

GREENPEACE, [R]evolução energética A caminho do desenvolvimento Limpo. Disponível em

<http://www.greenpeace.org/brasil/Global/brasil/report/2010/11/revolucaoenergeticadeslim po.PDF>. Acesso em 03 jun. 2011.

MMA - Ministério do Meio Ambiente, disponível em <http://www.ana.gov.br/Institucional/default.asp>. Acesso em 10 jul. 2011. 


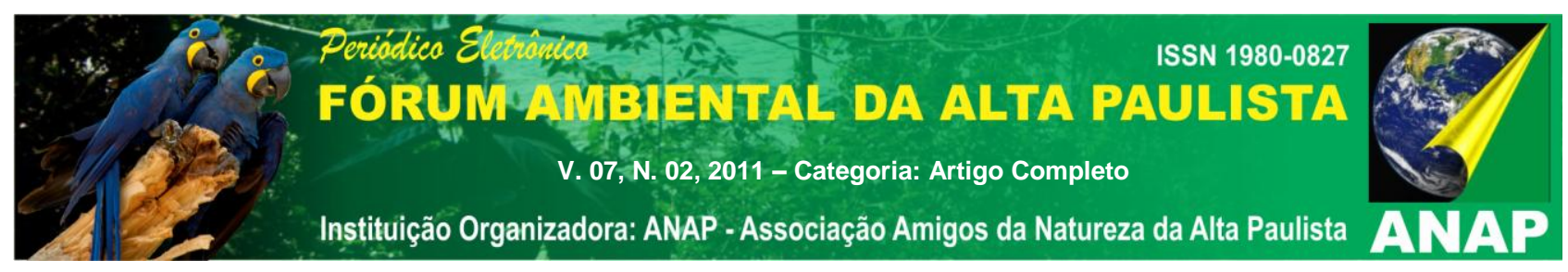

MULLER, A. C. Hidrelétricas, meio ambiente e desenvolvimento. 1.ed.São Paulo: Makron, 1995. $412 p$

PALZ, Wolfgang. Energia solar e fontes alternativas. São Paulo. Hemus livraria editora Itda, 1981.

PRADO, F. M. R. F. HIDRELÉTRICAS E PCHS SOBRAL 2010. Disponível em: <http://www.ebah.com.br/t2-hidreletricas-e-pchs-doc-a72401.html>. Acesso em $280 u t .2010$.

Piza. M. W. T. Hidreletricidade: impactos e participação na matriz energética nacional. 2011

SETTI, A. A. et al. Introdução ao gerenciamento dos recursos hídricos. 2. ed. Brasília: Agência Nacional de Energia Elétrica; Superintendência de estudos e informações hidrológicas, 2001. 207p.

UNIFEI - Universidade Federal de Itajubá, Curso de especialização em pequenas centrais hidrelétricas. Itajubá, 2009. 